\title{
Iterative surgical demolition and reconstruction of the anterior chest wall and thoracic outlet for a recurrent chondrosarcoma: long term oncologic and functional results-case report
}

\author{
Giulia De Iaco, Debora Brascia, Angela De Palma, Giuseppe Garofalo, Ondina Pizzuto, Valentina Simone, \\ Angela Fiorella, Giulia Nex, Marcella Schiavone, Francesca Signore, Teodora Panza, Giuseppe Marulli \\ Thoracic Surgery Unit, Department of Emergency and Organ Transplantation (DETO), University Hospital of Bari, Bari, Italy \\ Correspondence to: Prof. Giuseppe Marulli, MD, PhD. Thoracic Surgery Unit, University Hospital of Bari, G. Cesare Square 11, 70124 Bari, Italy. \\ Email: giuseppe.marulli@uniba.it.
}

\begin{abstract}
Chondrosarcoma is a cartilage-producing neoplasm, with a preferential location in the chest wall at the level of the sternum and the ribs. Prognosis depends from several factors, such as tumour grading and radicality of resection. Due to chemo and radio resistance, surgery including radical removal of the tumour and reconstruction of the rib cage is the main treatment, with radiotherapy reserved in case of R1 or R2 resection. We report a case of a 56-year-old patient affected by sternocostal chondrosarcoma submitted to several chest wall resections and reconstruction due to the multiple relapses reporting surgical strategy, and its impact on quality of life and respiratory function.
\end{abstract}

Keywords: Chest wall; chondrosarcoma; surgery; sternum; recurrence; case report

Received: 29 December 2019; Accepted: 10 February 2020; Published: 25 May 2020.

doi: $10.21037 /$ ccts.2020.02.03

View this article at: http://dx.doi.org/10.21037/ccts.2020.02.03

\section{Introduction}

Chondrosarcoma is the most common malignant tumour of sternum, clavicles and ribs, producing cartilage and having an intramedullary localization in $90 \%$ of cases. It is a disease preferentially affecting young men (M:F =2:1) and 5-year overall survival depends from several factors of which the most common is differentiation/grading. Because of chemoand radiotherapy resistance, surgical resection with wide margins and reconstruction of chest wall is considered the treatment of choice allowing a 5 -year survival rate above $75 \%$ (1). Herein, we present the case of a 56-year-old patient, affected by chest wall chondrosarcoma since 1998 who underwent iterative successful surgical resections of chest wall due to due local relapse of the disease. We present the following case in accordance with the CARE Guideline.

\section{Case presentation}

A 56-year-old man is actually under radiological follow up in our operating unit for a grade 2 chondrosarcoma, involving upper sternum, ribs and clavicles. Disease onset was in 1996 when patient, aging 33-year-old, felt thoracic pain, corresponding to the right costoclavicular joint. Medial part of the first right rib was removed and histological exam revealed a myxoid ossificans fibro-chondroma. Two years later, a painful swelling appeared in the area of the previous operation and the patient underwent to removal of median edge of right clavicle, right half of the sternal handlebar, resection of the residual right first rib and medial part of second right rib, with reconstruction through Mersilene mesh and coverage with myocutaneous latissimus dorsi flap. Postoperative course was complicated by pulmonary embolism requiring temporary $\mathrm{O} 2$ - and anticoagulation therapy. Histology was reported similar to the first one and the margins were disease-free. The patient was followed up with annual chest CT-scan remaining disease-free for 11 years.

On September 2009, thoracic pain recurred with evidence at chest CT-scan of a new bone tumefaction of 

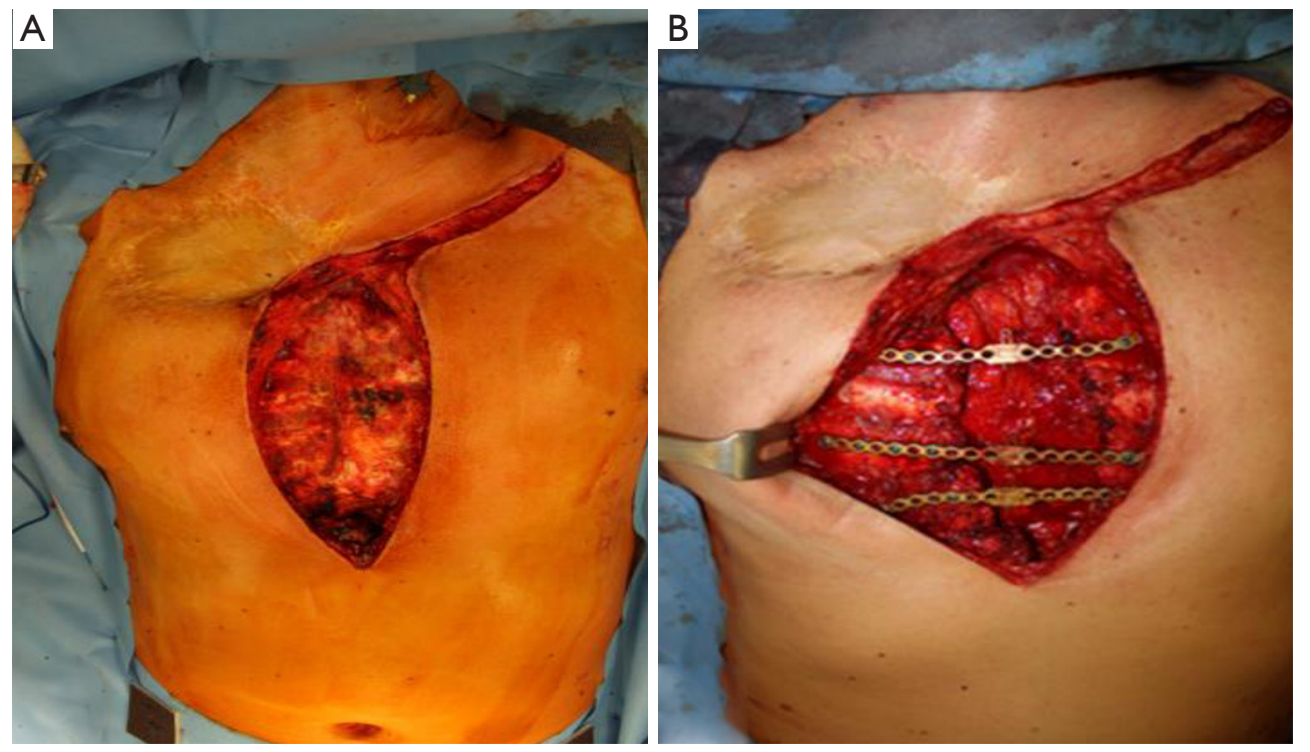

Figure 1 Chest wall demolition and reconstruction. (A) Intraoperative view of the upper sternal mass before sternectomy and (B) reconstruction with titanium plates after sternectomy.

the first left rib and left sternoclavicular joint suspected of disease recurrence. PET/CT-scan was positive with high uptake in this area, therefore the patient underwent a partial removal of medial part of first left rib after disarticulation of left clavicle; also in this case histological diagnosis was compatible for a benign costal osteochondroma. In June 2011, a new PET/CT-scan done for pain persistence showed a pathologic tracer uptake at the level of a left sternoclavicular tumefaction, thus the patient underwent a new operation: a resection of middle edge of left clavicle and remaining part of sternal handlebar were done. In this case, histological diagnosis was grade 2 chondrosarcoma infiltrating bone and soft tissue, the surgical margins were disease-free and the operation was considered R0. Previous histological slides were revised confirming the diagnosis of chondrosarcoma also in the other surgical specimens. During follow-up a PET/CT-scan performed seven months later revealed a significant uptake in the residual upper sternum highly suggestive for a local recurrence, therefore on January 2012 a complete sternectomy was performed with stabilization of anterior chest wall by three titanium plates fixed with screws between III, V and VII ribs bilaterally and covered with Mersilene mesh (Figure 1). Histology confirmed the presence of chondrosarcoma in the specimen at the level of upper sternum with surgical margins free of disease. Considering the history of multiple local relapses, postoperative adjuvant radiotherapy (total dose 60.4 Gy) on anterior chest wall was performed with no complications. Patient lived without any sign of disease for 4 years, but on September 2016 left thoracic pain recurred and PET/CT-scan revealed a moderate uptake in the anterior arch of the left $2^{\text {nd }}$ rib. Therefore, a total removal of left $2^{\text {nd }}$ rib with vertebral disarticulation was undertaken; also in this case histological examination confirmed a local recurrence of chondrosarcoma. After this last surgical approach, because of post-surgical chest chronic pain, a spinal cord stimulation was placed.

During radiological follow-up, in October 2018, PET/ CT-scan disclosed a new pathologic uptake at the level of residual medial part of the right $2^{\text {nd }}$ rib highly suggestive for a relapse of disease. Also in this case a complete rib removal through costovertebral disarticulation was performed with histological confirmation of chondrosarcoma relapse. At the last follow-up (December 2019) the patient is alive and free of disease, with persistence of mild chronic pain (Figures 2,3). Despite the multiple chest wall resections, pulmonary function was preserved [forced expiratory volume in the 1st second (FEV1): $2.49 \mathrm{~L}-77 \%$, forced vital capacity (FVC): $2.97 \mathrm{~L}-73 \%$, diffusing capacity for carbon monoxide (DLCO): $4.37 \mathrm{~mL} / \mathrm{mHg} / \mathrm{min} / \mathrm{L}-104 \%$ ].

All procedures performed in this study were in accordance with the ethical standards of the institutional and national research committees and with the Helsinki Declaration (as revised in 2013). Written informed consent 


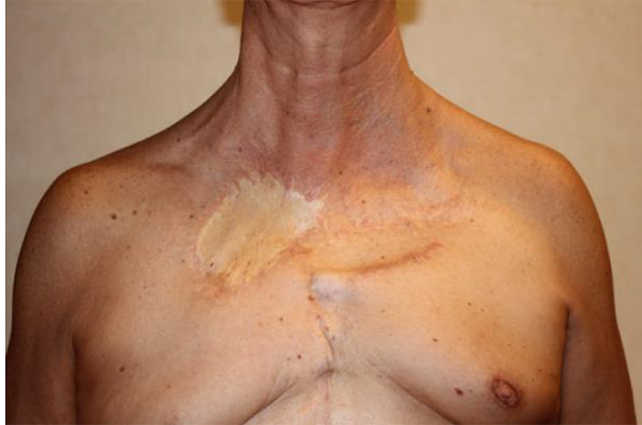

Figure 2 Aesthetic result after multiple surgical approaches.

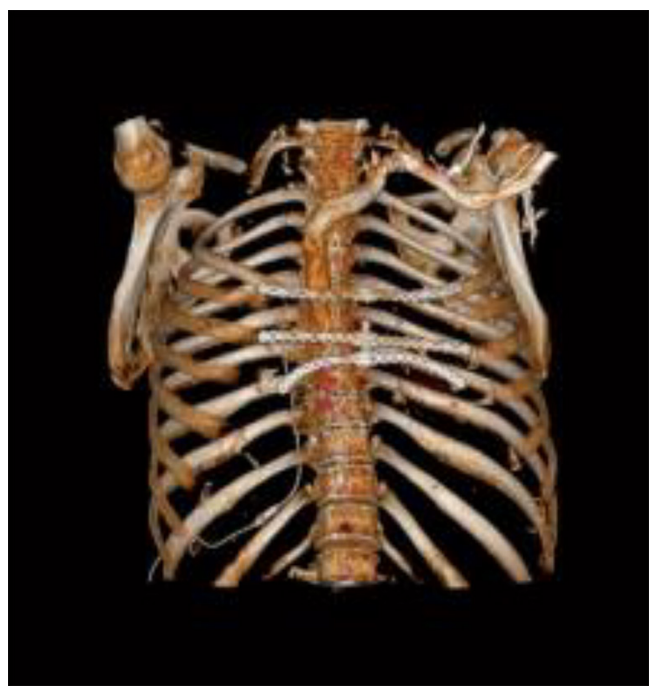

Figure 3 Chest CT-scan 3D reconstruction after the last surgery. The titanium plates are in place, the chest wall defect with the absence of the sternum, anterior portion of both clavicles and first ribs and complete $2^{\text {nd }}$ ribs removal bilaterally is evident.

was obtained from the patient for publication of this case report and any accompanying images. A copy of the written consent is available for review by the editorial office of this journal.

\section{Discussion}

Chondrosarcoma is the most common bone sarcoma in adults and has an annual incidence of about $2-3$ cases per million in the adult population (2-4). Sternum and ribs are affected in fifty-eight percent of cases, making it to be the most frequent primary malignant chest wall tumour. Generally, this tumour is diagnosed because of its big sizes and pain and in many cases CT scan reveals metastases $(5,6)$. In our patient first symptom of chondrosarcoma was pain but tumefaction or nodules were not reported. Radical en bloc excision with wide margins is the primary treatment for chest wall chondrosarcoma, because of its chemo-radio resistance $(2,3,7,8)$. In 1985 Mayo group reported a 10-year survival rate of $96.4 \%$ for those who had large resection, compared with $65.4 \%$ of the group of patients receiving local excision with short disease-free margin only (9). In 1992, the group of memorial Sloan Kettering Cancer Centre showed the results of analysis of their 40-year' experience on primary bony and cartilaginous chest wall malignancies: the single most important factor predicting survival was completeness of first resection (10). In our case, due to the wrong histological diagnosis after the first resection several local excisions with limited disease-free margins were performed, probably favouring the local recurrence of chondrosarcoma. However, the last two relapses on the second left and right ribs appeared after a radical resection of sternum and anterior ribs with wide margins. This also suggests a possible mode of intramedullary spread of the disease. Precisely for this reason we preferred the complete removal of the ribs up to their vertebral articulation in order to avoid any risk of new recurrence on the residual posterior portion of the ribs. The need for surgical resection with large disease-free margins leads to significant problems in the reconstruction techniques, therefore the main goal for surgeons is to re-establish thoracic stability and protect internal organs reaching a functional and aesthetic result. Our patient underwent many resections and removals of sternum, clavicles and ribs and reconstruction of chest wall was realised by placement of titanium plates and Mersilene mesh; also myocutaneous flap of latissimus dorsi contributed to reach this goal $(2,7,8,11-13)$. The staged and progressive procedures, allowing a stabilization of the residual chest cage probably avoided the risk of acute respiratory impairment that had could be higher in case of an en bloc resection in one stage of the anterior chest wall comprising the total sternectomy and clavicle bilaterally. Our patient not only had no respiratory complication, but also the joint and movements of the shoulder, arm and shoulder girdle were preserved. The use of titanium plates, as suggested by Gonfiotti et al., allows to guarantee stability of chest-wall, therefore reducing paradoxical movement also in wide chest-wall resections (7). After stabilization, the covering of defect may be undertaken in several ways but, as suggested by Chapelier et al. the use of muscular flap and many kinds of meshes is safe (14). 
Another target of reconstruction is preserving a good pulmonary function: in our patient last spirometric values are good and reveal a mild restrictive ventilatory deficit without any interference in normal daily activities.

\section{Conclusions}

First therapeutic approach to chondrosarcoma is radical removal with reconstruction of chest wall, considering chemo-radio resistance of this tumour. Reconstruction of thoracic wall with different materials and techniques should guarantee chest stability and protection of internal organs, preserve respiratory functions and allow a good quality of life.

\section{Acknowledgments}

Funding: None.

\section{Footnote}

Provenance and Peer Review: This article was commissioned by the Guest Editors (Francesco Zaraca, Reinhold Perkmann, Luca Bertolaccini and Roberto Crisci) for the series "Thoracic Surgery Without Borders" published in Current Challenges in Thoracic Surgery. The article has undergone external peer review.

Conflicts of Interest: All authors have completed the ICMJE uniform disclosure form (available at https://ccts. amegroups.com/article/view/10.21037/ccts.2020.02.03/ coif). The series "Thoracic Surgery Without Borders" was commissioned by the editorial office without any funding or sponsorship. GM serves as an unpaid editorial board member of Current Challenges in Thoracic Surgery from January 2020 to December 2021. The authors have no other conflicts of interest to declare.

Ethical Statement: The authors are accountable for all aspects of the work in ensuring that questions related to the accuracy or integrity of any part of the work are appropriately investigated and resolved. All procedures performed in this study were in accordance with the ethical standards of the institutional and national research committees and with the Helsinki Declaration (as revised in 2013). Written informed consent was obtained from the patient for publication of this case report and any accompanying images. A copy of the written consent is available for review by the editorial office of this journal.

Open Access Statement: This is an Open Access article distributed in accordance with the Creative Commons Attribution-NonCommercial-NoDerivs 4.0 International License (CC BY-NC-ND 4.0), which permits the noncommercial replication and distribution of the article with the strict proviso that no changes or edits are made and the original work is properly cited (including links to both the formal publication through the relevant DOI and the license). See: https://creativecommons.org/licenses/by-nc-nd/4.0/.

\section{References}

1. Gao H, Zhou Y, Wang Z, et al. Clinical features and prognostic analysis of patients with chest wall chondrosarcoma. Medicine (Baltimore) 2019;98:e17025.

2. Marulli G, Duranti L, Cardillo G, et al. Primary chest wall chondrosarcomas: results of surgical resection and analysis of prognostic factors. Eur J Cardiothorac Surg 2014;45:e194-201.

3. Abdel Rahman ARM, Rahouma M, Gaafar R, et al. Contributing factors to the outcome of primary malignant chest wall tumors. J Thorac Dis 2017;9:5184-93.

4. Lee FY, Mankin HJ, Fondren G, et al. Chondrosarcoma of bone: an assessment of outcome. J Bone Joint Surg Am 1999;81:326-38.

5. Ma XL, Wang DB, Ma JX, et al. Custom-made Prosthesis for Reconstruction after Radical Resection for Chondrosarcoma of Manubrium. Orthop Surg 2018;10:272-5.

6. Bansal D, Gupta A, Bhattacharya S, et al. Recurrent high-grade chondrosarcoma abutting the right ventricular outflow tract. Asian Cardiovasc Thorac Ann 2019;27:501-4.

7. Gonfiotti A, Santini PF, Campanacci D, et al. Malignant primary chest-wall tumours: techniques of reconstruction and survival. Eur J Cardiothorac Surg 2010;38:39-45.

8. Hann MC, Pettiford B, Babycos C. Novel Chest Wall Reconstruction Following Excision of an Xiphisternal Chondrosarcoma. Ochsner J 2018;18:180-2.

9. Nakashima Y, Unni KK, Shives TC, et al. Mesenchymal chondrosarcoma of bone and soft tissue. A review of 111 cases. Cancer 1986;57:2444-53.

10. Burt M. Primary malignant tumors of the chest wall. The Memorial Sloan-Kettering Cancer Center experience. Chest Surg Clin N Am 1994;4:137-54.

11. Yousefi Y, Sadrizadeh A, Sadrizadeh S. Huge sternal 
chondrosarcoma: a case report. Asian Cardiovasc Thorac Ann 2018;26:632-4.

12. Tounsi N, Zemni I, Abdelwahed N, et al. Costal chondrosarcoma mimicking a breast cancer: Case report and review of literature. Int J Surg Case Rep 2019;56:37-9.

13. Marulli G, Dell'amore A, Calabrese F, et al. Safety and Effectiveness of Cadaveric Allograft Sternochondral

doi: $10.21037 /$ ccts.2020.02.03

Cite this article as: De Iaco G, Brascia D, De Palma A, Garofalo G, Pizzuto O, Simone V, Fiorella A, Nex G, Schiavone M, Signore F, Panza T, Marulli G. Iterative surgical demolition and reconstruction of the anterior chest wall and thoracic outlet for a recurrent chondrosarcoma: long term oncologic and functional results-case report. Curr Chall Thorac Surg 2020;2:21.
Replacement After Sternectomy: A New Tool for the Reconstruction of Anterior Chest Wall. Ann Thorac Surg 2017;103:898-905.

14. Chapelier A, Macchiarini P, Rietjens M, et al. Chest wall reconstruction following resection of large primary malignant tumors. Eur J Cardiothorac Surg 1994;8:351-6; discussion 357. 